\title{
Entrevista al Alcalde Rodrigo Lara
}

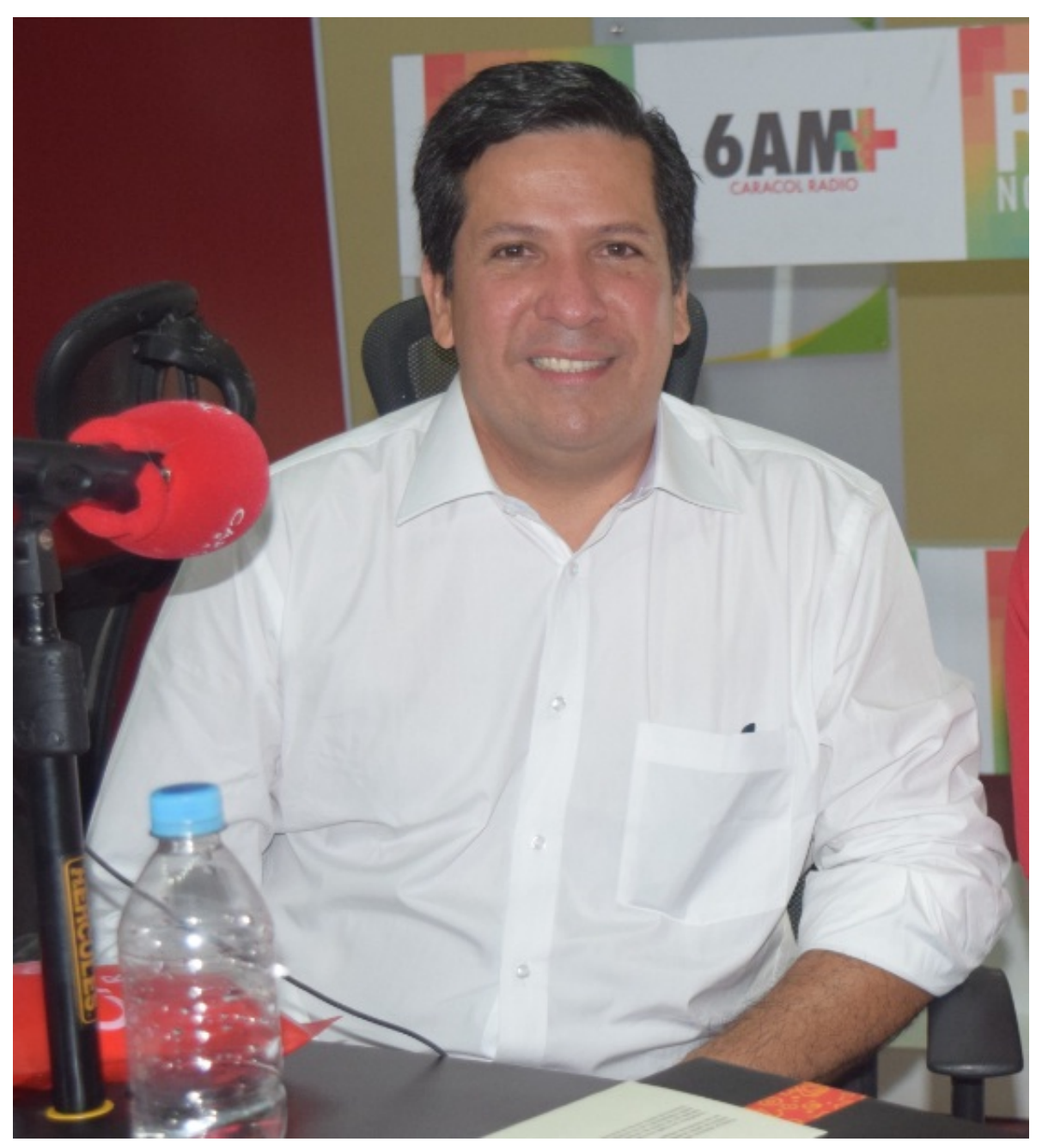

\begin{abstract}
Alexander Trujillo Baca
Profesor de Periodismo en la Universidad Surcolombiana, Máster en Periodismo Digital de la Universidad Oberta de Catalunya y Doctorando en Comunicación de la Universidad Nacional de la Plata-Argentina.
\end{abstract}

Rodrigo Armando Lara Sánchez, es un hombre de 48 años que ha vivido sus último 3 siendo el alcalde de Neiva, una de las ciudades capitales más importantes del sur colombiano. Hijo, no reconocido del inmolado Ministro de Justicia, Rodrigo Lara Bonilla, que un lunes 30 de abril de 1984, fue asesinado por orden del extinto narcotraficante Pablo Escobar.
Rodrigo Armando, es un hombre nacido y criado en, lo que los de la capital llaman, provincia. Médico de profesión egresado de la Universidad del Cauca, Especialista en Cirugía General de la misma Universidad, con una sub Especialidad en Cirugía de Tórax de la Universidad del Bosque y el Instituto Nacional de cancerología, Especialista en Gobierno y Gestión Pública de la Universidad Javeriana. Considerado 
en el 2017, según el noveno panel de opinión de la firma Cifras y Conceptos, como uno de los mejores alcaldes del país.

Es un hombre sencillo, que le gusta la academia parte de su vida la ha divido entre la medicina y la política. Ya en el 2011 Lara se había lanzado a la alcaldía de Neiva, perdiendo con Pedro Hernán Suárez de La U.

Nuevamente en el 2015, volvió a lanzarse para la alcaldía de la ciudad y quedó electo.

Entiende la educación, como un escenario indispensable para la transformación, y durante su gestión la Universidad Surcolombiana, la institución de educación superior más importante del sur colombiano.

Precisamente por ello, la revista Entorno, publicación científica de la Universidad Surcolombiana, conversó con él sobre la importancia de la educación superior y de cómo su administración ha coadyuvado junto con la Universidad a mejorar las condiciones de vida de los habitantes del sur colombiano.

Revista Entornos: ¿Qué tan importante es para usted y su Administración la universidad pública?

Rodrigo Lara: La universidad es el ente articulador del desarrollo de una región, debe ser el punto de partida de estudios, de investigación, donde se genere el conocimiento que permita la transformación social y la búsqueda del buen vivir; eso debe ser la universidad, un ente que articula a lo público con lo privado, que logra mirar la problemática desde un punto de vista, y desarrolla un papel primordial en el desarrollo de una región.

RE: ¿Cree que la Universidad Surcolombiana viene haciendo algo en pro de ese buen vivir?

RL: Sí, he visto y me he encontrado con muchas personas que son egresadas de la Universidad y hoy le sirven a la región; han logrado mejorar la calidad de vida, trabajan en diferentes instituciones y promueven el desarrollo, incluso desde entes donde se toman decisiones.

Particularmente nosotros tenemos un número importante de egresados aportando desde la Administración. Por ejemplo, el Secretario de Educación, el Jefe Jurídico, asesores míos, el Secretario de Ambiente y Desarrollo Rural, son egresados de la Universidad. Gente que trabaja desde lo público y privado y que ha ejercido ese papel de contribuir al desarrollo de la Región.

Sin lugar a dudas, en cincuenta años hemos vivido una transformación gracias en gran parte al aporte de los profesionales y dinámica de la Universidad.

Aun así, creo que falta muchísimo por hacer, pero no se puede desconocer el papel de la Usco en estos aspectos.

\section{RE: ¿En términos concretos dónde o en qué se observan esos aportes de la Universidad?}

RL: Por ejemplo, el mismo crecimiento de la Universidad, de empezar como un instituto y hoy ofrecer más carreras, posgrados, especializaciones, eso ha sido el empuje de los mismos profesionales que al interior de la Universidad han ejercido ese liderazgo para que esta también crezca de cara a la sociedad y las necesidades que tiene.

En el caso de nosotros, hoy Neiva tiene 200 maestros, es decir, el $10 \%$ de los maestros haciendo becas de maestría en un programa de alta calidad con la Universidad Surcolombiana, eso es un aporte de la Universidad al mejoramiento de la calidad de la educación. Hemos hecho también 700 diplomados con la Universidad. También hemos tenido una vinculación directa de la Surcolombiana en diferentes programas de formación con una visión social que de cierta manera impacta esta sociedad; tenemos mejores maestros, líderes y jóvenes gracias a la Universidad, eso nos ha ayudado a tener una mejor dirigencia en la ciudad. 
RE: ¿Se considera a la Universidad como un actor estratégico desde su Alcaldía para la transformación precisamente de esta ciudad?

RL: Sí, hemos logrado articular desde la administración un trabajo mancomunado con la Universidad en diversos aspectos anteriormente mencionados. Este apoyo que hemos tenido de la Universidad, ha sido retribuido a la Universidad en temas como el apoyo a la estampilla pro universidad para obtener recursos que fortalezcan la infraestructura de la institución.

RE: ¿Cuál es su balance del tiempo que lleva frente a la administración en relación a la articulación Alcaldía - Universidad?

RL: Me siento muy contento por lograr el convenio para becas de maestría en programa de alta calidad, hemos llegado a 200 becas; sin el apoyo de la Surcolombiana, hubiésemos llegado a la mitad.

Enriquecer y tener esos lazos directos con la Universidad, con facultades como la de Ingeniería en la asesoría de muchos proyectos que se adelantan, la de Medicina con el modelo integral de Salud, la de Ciencias Políticas en la formación de liderazgo ciudadano, ha permitido tener buenas relaciones y aportar a la sociedad, el propósito es hacerlas crecer más.

Somos una Administración que ha invertido mucho en infraestructura educativa, capacitación de maestros, dotación, bibliotecas, en primera infancia, lo que hemos hecho por la educación es histórico, porque nunca antes habíamos tenido tanta inversión y recursos destinados a estos propósitos, y ahí ha sido clave la Surcolombiana.

\section{RE: ¿Qué se debe mejorar?}

RL: Creo que la Universidad debe tener mayor proyección social; una mayor presencia en las comunas, en los barrios a través de todas sus facultades, es algo fundamental, es la búsqueda de soluciones construidas desde un conocimiento del territorio: la Universidad llega, conoce y plantea soluciones a las problemáticas. Ahí la Universidad podría jugar un papel más importante de lo que ha sido hasta el momento.

La Universidad Surcolombiana debe ser un órgano de acompañamiento técnico a las decisiones que se toman, por eso hay que fortalecer mucho más ese recurso que tiene la Universidad, los profesores, procesos de investigación, líneas de investigación, de tal manera que impacten en las decisiones y construcción de política pública.

RE: ¿Qué opinión le merece los escándalos en los que ha estado envuelta la Universidad?

RL: Eso es muy triste para la ciudad y para todos. Obviamente tener al Consejo de Neiva y la universidad pública, entes tan importantes, envueltos en un proceso tan difícil, no deja de preocupar. Esperamos que se aclaren todos estos temas ya que por encima de las personas están las instituciones.

Particularmente la Universidad no se debe quedar en esto sino que tiene superar todas estas dificultades y seguir desarrollando ese liderazgo, para ello necesita generar confianza y la confianza se construye. 